классов: автореф. дис. ... канд. пед. наук: 13.00.08. Самара, 2010. 22 с.

9. Липенская И.А. Формирование специальных компетенций бакалавра: профиль «Начальное образование»: автореф. дис. ... канд. пед. наук: 13.00.08. Самара, 2014. 25 с.

10. Федорова Т.В. Организационно-функциональная модель подготовки педагога к формированию у младших школьников умения прогнозировать: дис ... канд. пед. наук: 13.00.08. Самара, 2017. 270 с.

11. Федеральный государственный образовательный стандарт высшего образования, уровень высшего образования бакалавриат, направление подготовки 45.03.02 Лингвистика (приказ Министерства образования и науки РФ от 7 августа 2014 г. № 940).

\title{
DEVELOPMENT OF PROFESSIONAL COMPETENCIES OF STUDENTS, MAJORING IN «PEDAGOGICAL EDUCATION» («PRIMARY EDUCATION» AND «FOREIGN LANGUAGE»)
} (C) 2018

Kochetova Natalya Gennadyevna, candidate of physics and mathematical sciences, associate professor, head of Primary Education Department

Stroykov Sergey Aleksandrovich, candidate of philological sciences, associate professor of Foreign Languages Department

Samara State University of Social Sciences and Education (Samara, Russian Federation)

Abstract. The following paper considers development of professional competencies of students, majoring in «Pedagogical education» («Primary education» and «Foreign Language»). The authors analyze legal regulations to teacher training and correlate demands to the teacher that are enumerated in federal state educational standard of general secondary education, in federal state educational standard of higher education and in the professional standard «Teacher». The paper also contains Primary Education Department experience of professional competencies development. Based on the example of Professional Competence 4 development the authors introduce its components characteristics as well as diagnostic methods of this professional competence development. The authors note that it is necessary to develop special professional competencies of students, majoring in «Pedagogical education» («Primary education» and «Foreign Language»). Based on the example of Special Professional Competence (Foreign Language) 2 the authors introduce its components characteristics. The paper also contains problems that Primary Education Department and Foreign Languages Department face while developing professional competencies of students, majoring in «Pedagogical education» («Primary education» and «Foreign Language»).

Keywords: competence; professional competencies; special competencies; professional competencies development; components characteristics; teacher; pedagogical education; foreign language; standard; professional standard; methods; diagnostics.

УДК 372.857

Статья поступила в редакцию 07.01.2018

\section{СОСТОЯНИЕ ПРОБЛЕМЫ РАЗВИТИЯ УЧАЩИХСЯ В ТЕОРИИ И ПРАКТИКЕ ОТЕЧЕСТВЕННОЙ ШКОЛЫ ДО 1917 ГОДА (НА ПРИМЕРЕ ЕСТЕСТВОЗНАНИЯ)}

(C) 2018

\author{
Ламехова Елена Анатольевна, кандидат педагогических наук, \\ доцент кафедры общей биологии и физиологии \\ Южно-Уральский государственный гуманитарно-педагогический университет \\ (2. Челябинск, Российская Федеращия)
}

\begin{abstract}
Аннотащия. В статье рассматривается проблема взаимосвязи обучения, воспитания и развития учащихся в процессе изучения естественных наук, всегда интересовавшая педагогов и методистов. Особенно актуальна эта проблема сейчас в связи с дальнейшим внедрением ФГОС среднего общего образования, нацеливающего школу на создание условий для развития и самореализации обучающихся. Более подробно в статье рассматривается трактовка взаимосвязи обучения, воспитания и развития в образовательном процессе в отечественной педагогике в период до 1917 года. Отмечается, что педагоги России и Европы к идее взаимосвязи воспитания и развития в ходе обучения детей пришли примерно в одно и то же время. На протяжении всего исторического периода наблюдалась борьба между сторонниками нового образования, выступающими за сближение с передовой российской и западноевропейской наукой, и русским духовенством, проповедовавшим церковные догмы, и их противниками, отрицающими всякое развитие вообще. Достаточно долго нерешенными проблемами были отсутствие общепринятых программ для всех учебных заведений и согласованных сроков обучения. Принципиальные изменения в системе отечественного образования связаны с научной и педагогической деятельностью М.В. Ломоносова и его последователей. Подчеркивается важность появившейся в трудах педагогов в середине XIX века идеи о целесообразности учета возрастных и индивидуальных склонностей детей и разработке новой методики, построенной на активности и самостоятельности детей, которая позволила перейти к индуктивному пути обучения. Процесс изучение естествознания еще с XIX рассматривается как реальное и эффективное средство развития органов чувств, логического мышления и наблюдательности. Также дается объяснение необходимости сочетания индуктивного и дедуктивного метода обучения и обосновывается необходимость использования натуральных объектов, опытов и наблюдений в природе для развития учащихся.
\end{abstract}


Ключевые слова: обучение; воспитание; развитие; федеральный государственный образовательный стандарт среднего общего образования; самореализация; естествознание; учебники; учебные пособия; язык науки и образования; педагогические проблемы; дидактические проблемы; методические проблемы; индуктивный дедуктивный методы обучения; биологический метод.

Внимание к взаимосвязи обучения, воспитания и развития в образовательном процессе, наблюдаемое сейчас в связи с внедрением федерального государственного образовательного стандарта среднего общего образования, не является принципиально новым. В разные исторические периоды интерес к данной проблеме не угасал, только лишь немного менялись трактовки и содержание и, соответственно, ожидания от результатов этого взаимодействия. Признавая важность и актуальность развития детей в процессе обучения, современный образовательный стандарт нацеливает школу на создание условий для развития и самореализации обучающихся.

Для полноты представления об имеющемся опыте нам важно осуществить объективный анализ взглядов на проблему взаимосвязи обучения, воспитания и развития педагогов и методистов, работавших в России в период до 1917 года. Этот анализ продолжает исследования автора по проблеме реализации развивающей функции обучения в отечественном образовании [1-4].

Педагоги России и Европы к идее взаимосвязи воспитания и развития в ходе обучения детей пришли примерно в одно и то же время зачастую на основе сотрудничества. В России было много педагогов из стран Западной Европы, и, в свою очередь, наши педагоги и методисты активно изучали их систему работы во время работы за границей. Такое сотрудничество имеет свои определенные исторические корни.

Возникшее на рубеже VIII-IX веков раннефеодальное государство Русь было крупнейшим в Европе. Оно осуществляло торговлю и деловые сношения со странами Европы. В государстве были люди, владевшие иностранными языками и писавшие книги. Созданные ими в XI-XII веках рукописные переводные и оригинальные сборники содержали тексты педагогического содержания. Известно также, что в этих сборниках были опубликованы высказывания Сократа, Демокрита, Аристотеля.

В педагогической литературе того времени содержатся советы по воспитанию детей: как обеспечить физический рост и здоровье, умственное и нравственное развитие детей; как воспитывать у детей благочестие и почитание старших и т.д.

B XV-XVI веках в России, как и в Западной Европе, стали распространяться взгляды педагогов-гуманистов Ф. Курицына и первопечатника И. Федорова. В 1574 году Федоров издал первую славянскую «Азбуку», набранную кириллицей. Для него радостный процесс развития и воспитания сопоставим с идеей роста и развития растения, дающего цветы и плоды.

В XVII веке продолжалась борьба между сторонниками нового образования, выступающими за сближение с передовой западноевропейской наукой, и русским духовенством, проповедовавшим церковные догмы, и их противниками, отрицающими всякое развитие вообще.

Учебные книги XVII века были как печатные, так и рукописные. Для нас важным является то, что в них уже встречаются краткие статьи по природоведению и описанию различных животных.

К XVIII веку Россия превратилась в феодальноабсолютистское многонациональное государство. В нем развивалось мануфактурное производство. Для государства по-прежнему были необходимы грамотные люди, поэтому правительство Петра I начало проводить реформы в области культуры, науки и техники. В значительной степени реформы петровского периода были подготовлены изменениями в обучении во второй половине XVII века.

В XVIII веке в результате реформы система образования окончательно сформировалась как сословная. Именно в это время появляются на Урале первые горнозаводские школы [3]. В них учащимся давалась общеобразовательная и специальная подготовка для работы на открываемых заводах [5].

На наш взгляд, к нерешенным проблемам этого периода можно отнести отсутствие единых программ для всех учебных заведений и установленных сроков обучения, а также пестрый возрастной состав обучающихся [3].

Учебные книги XVIII века были и русских авторов (Л. Магницкий, М. Смотрицкий и др.), и иностранных авторов в переводе (Я. Коменского и др.).

В 1725 г. в Петербурге была открыта Академия наук. Университет и гимназия, созданные при ней, подготовили многих выдающихся ученых и специалистов.

М.В. Ломоносов (1711-1765) был выдающимся разносторонним ученым, сыгравшим важную роль в развитии отечественной педагогики, и талантливым педагогом, впервые начавшим читать лекции и писать научные труды на русском языке. Он много сделал для обогащения русского языка научными терминами. Он был активным и последовательным борцом за просвещение народа, стремился приобщить молодежь к познанию отечественных природных богатств и содействовал введению преподавания естествознания в народных училищах. Это было очень актуально потому, что до того времени такого предмета в училищах не было.

М.В. Ломоносов и его соратники с самого начала деятельности Московского университета интенсивно разрабатывали педагогические, дидактические и методические проблемы.

В дальнейшем идеи М.В. Ломоносова развивались в работах Н.П. Половского, А.А. Варсова, Х.А. Чеботарева и других. Так, например, Х.А. Чеботарев (17451815) в работе «Слово о способах и путях, ведущих к просвещению» (1779 г.) указывал, что «самонадежными дорогами, ведущими к учености, являются следующие: "хороший порядок учения", "хорошее наставление и обучение", "выбор и чтение книг", "ученые путешествия по тем землям, где эти науки процветают" и "ученые состязания-диспуты"».

Активный участник московского «Географического общества», педагог-просветитель Н.И. Новиков (1744-1818) был в своем роде просветителем, так как содействовал переводам и изданию на русском 
языке книг известных западноевропейских педагогов и философов Я. Коменского, Дж. Локка, Ж.Ж. Руссо [3]. Кроме этого, Н.И. Новиков в своих работах отстаивал необходимость бессословного образования. Он писал, что основная задача школы - подготовка образованных, свободных и благородно мыслящих людей, способных бескорыстно трудиться на благо отечества. Детей необходимо научить «способности исследовать», разум их должен быть упражняем и обогащен. Для этого необходимо давать, наряду со знаниями счета и грамоты, также сведения об окружающей природе, чтобы «научить детей мыслить основательно». Нравственное воспитание, по Новикову, позволит привить детям чувство любви к людям и труду [5, с. 89].

Несколько иных взглядов на образование и воспитание детей придерживался И.И. Бецкой (17041795). В частности, он утверждал, что для улучшения общественной жизни надо воспитать «новую породу людей» в закрытых учебных заведениях в страхе перед богом. В обучении детей необходимо учитывать «природу, пол и склонности» каждого ребенка, «просвещая при том их разум наукам и художествам ...». Процесс обучения, по Бецкому, должен быть приятным для учеников, без принуждения и идти «больше от смотрения и слушания, чем от твержения уроков» $[5$, с. 75]. Особенно ценно его стремление воплотить в жизнь идеи передовых западноевропейских педагогов.

Приглашенный в Россию для проведения реформы образования сербский педагог Ф.И. Янкович (1741-1814) был активным последователем Я. Коменского и крупным дидактом. Благодаря его деятельности впервые в учебный план всех училищ было введено естествознание («естественная история»). Он издал дидактический трактат «Руководство учителям народных училищ», рекомендовал учителям в обучении обращаться не столько к памяти учащихся, сколько к их разуму и при изучении «естественной истории» пользоваться наглядными объектами и таблицами. Поскольку трактат Янковича считался официальной дидактикой, то можно считать, что он внес свой вклад в становление преподавания естествознания в России [5].

Развивая взгляды М.В. Ломоносова на обучение и воспитание детей, А.А. Радищев (1749-1802) решительно настаивал на том, чтобы отечественный русский язык стал языком науки и образования. Он считал, что основной задачей обучения и воспитания является воспитание людей с твердым, благородным характером, способных применить свои знания на практике, умеющих работать умственно и физически, обладающих эстетическими чувствами и высокими моральными качествами. Во многом возражая и критикуя Руссо, он был согласен с теми, кто призывал считаться с природными особенностями детей. Но ведущим элементом воспитания А.А. Радищев считал не природные задатки детей, а обстоятельства (социальные факторы), окружающие человека. В этом он был близок к идеям Дж. Локка.

Между русскими естествоиспытателями и натуралистами Запада в тот период существовала активная связь. К. Линней (1707-1778), Ш. Бонне (17201793), М. Адамсон (1727-1806), Л. Споланцани (1729-1799) не только вели с русскими академиками научную переписку, но и принимали непосредственное участие в трудах Академии.

Русские ученые имели авторитет у своих западноевропейских коллег, поскольку осуществляли серьезные исследования в области естественных наук. Но также ценным является и то, что они, переводя работы современных им ученых, стремились к дальнейшему просвещению подрастающего поколения. Так, например, была переведена «Естественная история» французского натуралиста Ж. Бюффона в 36 томах отечественными учеными В.М. Севергиным, В.Ф. Зуевым и др.

Первым отечественным методическим и учебным руководством по естествознанию по праву можно считать написанную В.Ф. Зуевым книгу «Начертание естественной истории, изданное для народных училищ Российской империи». В свет книга вышла в 1786 году и послужила основой для становления системы обучения естествознания, поскольку она основывалась на научных идеях Ломоносова и Радищева о том, что природа является единым целым [3].

Подходы В.Ф. Зуева близки к идеям отечественных и западноевропейских ученых. Развивая утверждения М.В. Ломоносова и А.А. Радищева о единстве опыта и теоретического мышления и неразрывной связи практики и теории, В.Ф. Зуев в указаниях по методике преподавания, изложенных во введении, отмечал, что «из школьника надо воспитывать исследователя». Преподавание должно было идти путем беседы, активизирующей процесс мышления и способствующей более сознательному усвоению материала. В ходе беседы следует рассматривать не только внешние черты строения предметов природы, но и вскрывать их сущность и развитие. Особенно актуальна в настоящий момент мысль В.Ф. Зуева о том, что обучение должно быть наглядным и предметным, с использованием натуральных объектов и подлинных образцов живых растений и животных. Применять в обучении таблицы и картины допустимо лишь в крайнем случае, поскольку чувственное восприятие должно преобладать. В этом его подход близок с принципом наглядности в обучении, сформулированным Я.А. Коменским.

Вместе с тем учитель, работающий по учебнику, мог построить обучение на правильной научной основе, поскольку В.Ф. Зуев был ученым биологом, много работавшим в экспедициях, и «Начертание естественной истории ...» написано в соответствии с передовыми сведениями по естествознанию [3].

Для улучшения усвоения материала учебник написан простым, ярким и образным русским языком. Признавая необходимость развития своего родного языка, В.Ф. Зуев активно работал над созданием русской научной биологической терминологии [6].

Анализируя учебник, можно отметить и то, что развитию умственной деятельности учащихся способствовало сравнительное описание растений и животных по сходным и отличительным признакам и расположение материала с делением на части и параграфы, выделением в тексте другим шрифтом новых названий и терминов. Развитию памяти и воображения способствовала точность и немногословность определений и характеристик [3].

На протяжении нескольких десятилетий учебник В.Ф. Зуева «Начертание естественной истории ...» 
(1786 г.) был лучшим и наиболее используемым в практике народных училищ [7], потому что, несмотря на повсеместное введение естествознания (естественной истории) как учебного предмета, первоначально не было программы и методического руководства и учителя могли ориентировать только на учебник.

Вышедшие позднее учебники А.М. Теряева [8] и И. Кастальского [9] содержали дополнительную информацию по систематике растений, но в разной степени способствовали развитию учащихся. Занимаясь по учебнику Теряева, дети в основном тренировали память, заучивая наизусть детали морфологического описания растения. Учебник И. Кастальского учитывал особенности детей школьного возраста, был доступен, носил научный характер, следовал дидактическим принципам, установленным еще Я.А. Коменским, и поэтому более способствовал развитию учащихся.

В силу сложившихся политических обстоятельств и антинародной реформы образования, проведенной правительством Николая I, естествознание, как «способствующий развитию свободомыслия предмет», в 1828 году было изгнано из гимназий и училищ [3].

В этот период продолжалось совершенствование передовой педагогической мысли. Так, В.Ф. Одоевский (1804-1869) писал, что надо не передавать человеку знания, а стараться, чтобы он получил способность сам доходить до них, т.е. «человек, умеющий учиться, выучится всему в короткое время, что бы ни понадобилось ему в продолжении жизни» [5, с. 110]. Но этому ребенка надо научить [5, с. 112]. Он пошел дальше И.П. Песталоцци и А. Дистервега, подчеркивая необходимость разработки национальных и психологических основ педагогической науки.

Н.И. Лобачевский (1792-1856) и В.Г. Белинский (1811-1848) в своих статьях и выступлениях, наряду с необходимостью развивать у детей умственные способности, говорили о важности «развития чувства изящного» (по Белинскому) или «образованности вкуса» (по Лобачевскому) [5, с. 135; 5, с. 115]. Очевидно, они имели в виду развитие духовных потребностей человека, его эмоциональной сферы.

Также была близка В.Г. Белинскому мысль о целесообразности учета возрастных и индивидуальных склонностей детей и о внедрении новой методики обучения. Эта методика, построенная на активности и самостоятельности, позволит перейти к индуктивному пути обучения (в отличие от распространенного тогда догматического обучения).

В этот период русские ученые (И.Е. Дедьковский, П.Ф. Горянинов, К. Бэр, И. Рулье, А.Н. Бекетов, А.Н. Северцов), опираясь на опыты по изучению природы и практики сельского хозяйства, разрабатывали теоретические проблемы естествознания и выдвигали новые убедительные доказательства исторического развития природы. Их научная деятельность и настойчивые требования включить естественную науку в курс учебных заведений, а также определенные социально-экономические и политические условия развития России привели к возвращению с 1852 г. естествознания в гимназии и училища [3].

Вместе с тем необходимо отметить стремление педагогов и методистов учесть возрастные особенности детей и сделать обучение более доступным уча- щимся. В этот период в отечественной школе начинают постепенно формироваться два метода обучения - индуктивный и дедуктивный. Больше сторонников было у дедуктивного метода изучения растений и животных, при котором сначала давалась общая характеристика типа (класса), затем по единому плану изучали представителей более мелких групп. Но это приводило, как правило, к преобладанию зубрежки, а следовательно, к притуплению мыслительной деятельности и понижению интереса к изучению природы [3]. Причиной этой проблемы можно считать отсутствие опубликованных методических указаний по преподаванию отдельных тем и предметов в целом.

На состоявшемся в 1861 году первом съезде естествоиспытателей обсуждался вопрос о содержании и значении преподавания естествознания в средних учебных заведениях. После обсуждения участники пришли к выводу, что изучение естествознания наиболее действенное средство развития органов чувств, логического мышления и наблюдательности.

Важность преподавания естествознания для развития учащихся понимали как ученые, так и педагоги. К.Д. Ушинский (1824-1870) также подчеркивал значение изучения природы для развития детей. Критикуя спор сторонников формального и материального образования, он писал, что для правильного развития и воспитания учащихся одинаково актуальны как развитие умственных сил и способностей, так и овладение знаниями, имеющими практическую ценность [3]. Противопоставление этих направлений бессмысленно, так как при следовании только одному из них воспитание получится однобоким. Естественные науки должны стать, по Ушинскому, такими же обыкновенными, как грамматика и арифметика [10].

Являясь знатоком педагогических и психологических взглядов зарубежных коллег прошлого и современного ему периодов, К.Д. Ушинский был сторонником Я. Коменского, И. Песталоцци, А. Дистервега. Он считал, что в обучении, сообразуясь с природой, надо идти от конкретного к абстрактному, от представления к мысли, т.е. следовать по индуктивному пути. В этом он противоречил широко распространенному тогда в России дедуктивному методу изучения материала [11]. Поскольку К.Д. Ушинский стремился исходить из опыта и придавал большое значение наблюдению, ему были близки идеи эмпирической психологии, утверждающей, что развитие психической жизни человека происходит в конкретной среде и от этого зависит.

Сходные идеи о значении индуктивного метода для развития мышления высказывали известные русские ученые XIX в. - профессор ботаники А.Н. Бекетов (1825-1902) и профессор зоологии А.П. Богданов (1834-1896) [3]. Работая с разными биологическими объектами, они утверждали, что наблюдения, работа с живыми и фиксированными объектами должны способствовать активизации мышления учащихся. А.Н. Бекетов обосновал это утверждение на основе работы с ботаническими объектами [12], а А.П. Богданов - при работе с животными объектами. Также А.П. Богданов утверждал, что следование таким методическим приемам, как обучение учащихся сравнению новых знаний с ранее изученными, должно способствовать активизации мышления учащихся [13]. 
Профессор А.Н. Бекетов перевел на русский язык учебник ботаники прусского педагога А. Любена (1804-1873). А. Любен в основу своих правил обучения естествознанию положил 4 принципа дидактики Я.А. Коменского [3]. Главным методом преподавания являлось самостоятельное сравнение учащимися объектов природы. Он считал, что упражнять ученика в сравнении - значит приучать его к глубокому наблюдению и мышлению. Именно изучение естествознания, по Любену, приводит к развитию мышления, органов чувств, наблюдательности, памяти [14].

С учетом методических подходов А. Любена в России были подготовлены и вышли в свет учебники ботаники [15] и зоологии [16; 17].

Опираясь на имеющийся положительный и отрицательный опыты работы по дедуктивному и индуктивному методу, А.Я. Герд (1841-1888) положил начало научной методике преподавания естествознания [3]. Предлагая в учебной работе объединить индуктивный и дедуктивный метод, он учитывал особенности психологии детей школьного возраста и подчеркивал, что только в этом случае возможна реализация основной цели преподавания естествознания в школе. Под ней он понимал следующее: в ходе изучения естествознания ум учащихся должен обогащаться постепенно расширяющимися обобщениями, у учащихся должны постепенно появляться интерес к науке и потребность к дальнейшему расширению приобретенных знаний. Для развития ума учителя должны обучать учащихся умению наблюдать, сравнивать, обсуждать увиденное, делать выводы и обобщения и проверять их простыми доступными опытами. Важным в ходе изучения естествознания А.Я. Герд считал также эстетическое воспитание и приобретение практических навыков [18].

А.Я. Герд в своей работе пошел дальше, чем его предшественники и доказал, что полноценное всестороннее развитие учащихся при обучении естествознанию возможно при проведении взаимосвязанных уроков, экскурсий, домашний заданиях и чтении [3].

Его современник, профессор анатомии П.Ф. Лесгафт (1837-1909), опираясь на глубокое знание психологических и физиологических особенностей развития детей дошкольного и школьного возраста, выдвинул новую педагогическую теорию о всестороннем развитии личности с учетом влияния психических и физиологических процессов. Он отрицал наследственную обреченность в развитии человека и признавал решающую роль среды в воспитании человека [19]. П.Ф. Лесгафт подчеркивал, что между умственным и физическим образованием существует тесная связь и образование идет по одним и тем же законам [5, с. 315].

П.Ф. Лесгафт сформулировал еще один метод изучения природы - естественно-исторический. Он утверждал, что работа по этому методу будет способствовать развитию мышления. Этот метод включает: формирование образа в умах учеников со слов учителя; возникновение необходимости проверки правильности образа; проверка учащимися правильности образа путем наблюдения, сравнения, опытов и т.д. На этом этапе происходит наглядное восприя- тие: у учащихся развивается умение координировать получаемые восприятия, представления и мышечные ощущения. Предлагаемый П.Ф. Лесгафтом метод имел большое число сторонников и широко использовался в обучении [3].

Несомненным «плюсом» его утверждений является то, что всестороннее развитие личности возможно только с учетом психических и физиологических особенностей возрастного периода, «минусом» можно считать его отказ от наследственной обреченности и преувеличение роли среды в воспитании человека.

Сторонник рассмотренного метода, В.В. Половцов (1862-1918) в своем докладе на ХІ съезде русских естествоиспытателей и врачей определил преподавание естествознания как процесс, имеющий воспитательное и развивающее значение [3], поскольку в ходе него происходит психическое развитие детей, упорядочение и дальнейшее развитие методов мышления и нравственной личности учащихся [6].

Его идеи, сформулированные в более поздней и основательной теоретической работе «Основы общей методики естествознания», показывают, что он постепенно отошел от метода П.Ф. Лесгафта и предлагал строить обучение на наблюдениях и опытах: опираясь на них, ученик сможет создать представление о предметах (объектах). В.В. Половцов отмечает ведущую роль индуктивного метода, поскольку этот метод лучше развивает органы чувств [3]. Развитие мышления, по В.В. Половцову, возможно тогда, когда, используя индуктивный метод, учитель научит учащихся устанавливать ряды последовательных явлений «так, чтобы каждый предшествующий составлял необходимое условие появления последующего» [20]. Таким образом В.В. Половцов обосновывает свой «биологический метод». Этот метод в целом способствовал развитию мышления, наблюдательности и памяти у учащихся.

О необходимости идти в изучении естествознания преимущественно индуктивным путем говорил и Б.Е. Райков (1880-1966). Развивая идею В.В. Половцова о преобладании индуктивного метода, он говорит о важности практических работ для успешного усвоения сведений по естествознанию и обосновывает два метода проведения практических занятий иллюстративный и исследовательский. Разница в использовании этих методов заключалась в том, что в первом случае ученики работают уже после изучения нового материала, а во втором - опыты и наблюдения учащиеся проводят самостоятельно на неизвестном материале [3]. Учитель в этом случае выполняет роль консультанта и советника. Второй метод, по Райкову, более ценен, так как он полнее развивает самодеятельность, находчивость, предприимчивость и мышление школьников. При этом ученик получает, считал он, не только знания, но и умения и навыки [6]. Особенно это столкновение мнений и позиций актуально в нынешней ситуации, в условиях перехода отечественной школы к реализации ФГОС.

На реализацию связи теоретических знаний с практическим трудом, обучение умению вести наблюдения летом в природе и проводить несложные опыты были направлены тетради «Наблюдай приро- 
ду» Б. Игнатьева и С. Соколова [21]. Они в значительной степени способствовали развитию двигательных навыков учащихся. Простота и доступность заданий в тетрадях послужили причиной их долгой популярности среди учителей школ [3].

В России на рубеже XIX и XX вв. у истоков формирующихся как самостоятельные науки возрастной и педагогической психологии стояли В.М. Бехтерев, А.Ф. Лазурский, А.П. Нечаев, И. Эвергетов и другие. В своих работах и статьях авторы наряду с изложением собственных идей использовали также результаты исследований западноевропейских и американских психологов Г. Спенсера [22], Т. Рибо [23], А. Бинэ и Т. Симон [24] и других. Это подтверждает хорошее знание отечественными психологами идей их зарубежных коллег.

Но общей идеей, объединяющей все статьи и публикации, является признание авторами возможности развития детей в процессе воспитания и обучения и важности для родителей и воспитателей знакомства с психологией детского возраста и с душевной жизнью детей, а также индивидуальными особенностями их развития $[25$, с. 6$]$.

Сторонниками передовых взглядов на психическую жизнь и развитие детей были и методистыестественники. Так, Л.С. Севрук (1867-1918) считал, что методы обучения школьников должны соответствовать возрастным закономерностям развития психики ребенка. Он писал, что у детей работает не только память, но и воображение и мысль, и работают они так же энергично, как и у взрослых [3]. Для содействия развитию детей учитель должен как можно шире в процессе обучения применять индукцию, дедукцию, анализ, синтез и т.д. В процессе обучения следует учитывать индивидуальные особенности ребенка и обеспечивать активное участие учащихся в уроке. Только выполнение всех этих требований обеспечит развитие детей [26].

И.И. Полянский (1872-1930) подчеркивал, что в основе преподавания школьного естествознания должны лежать познавательные процессы. Ведущим методом обучения он, как и Б.Е. Райков, считал индуктивный метод, а в выборе материала он руководствовался «биологическим методом» В.В. Половцова [6]. В отличие от других авторов пособий, он предлагал изучать объекты от высших к низшим, т.е. ошибочно считал такое расположение наиболее соответствующим возрастному восприятию [6].

Таким образом, анализируя педагогические и методические взгляды педагогов дореволюционного периода, можно сказать, что идеи психологов были им близки и педагоги старались использовать результаты их исследований для обеспечения развития учащихся в процессе обучения. Также следует отметить, что передовые педагоги и методисты того времени наряду с различением индуктивного и дедуктивного метода обучения отмечали необходимость использования биологического метода, в котором особенно значимо использование живых объектов и работа в природе. Идея сочетания разных форм классно-урочного обучения и непосредственных наблюдений за объектами вне уроков перекликаются с расширенным вниманием в настоящее время к внеурочной работе по биологии в ее разных вариантах. Следовательно, мы можем говорить о том, что опыт обеспечения развития учащихся на основе взаимосвязи обучения и воспитания, накопленный в отечественной школе до 1917 года, является не только интересным, но и полезным для совершенствования образовательного процесса в настоящий период в свете реализации ФГОС.

\section{Список литературы:}

1. Ламехова Е.А. К возможности реализации развивающей функции обучения в преподавании биологии // Сборник научных статей аспирантов Челябинского государственного педагогического университета / под ред. проф. В.Я. Рушанина. Челябинск: ЧГПУ, 1997. С. 36-38.

2. Ламехова Е.А. О реализации развивающей функции обучения в преподавании ботаники в средней школе // Развивающее образование: современные проблемы: сборник трудов российской конф. (3031 октября 1997 г.). Челябинск / под ред. проф. Н.Н. Тулькибаевой. Челябинск: ООО «Факел», 1997. C. $77-78$.

3. Ламехова Е.А. Реализация развивающей функции обучения в преподавании биологии в средней школе: дис. ... канд. пед. наук: 13.00.02. М., 1998. $189 \mathrm{c}$.

4. Ламехова Е.А. Анализ состояния проблемы развития детей в процессе обучения в трудах ученых XIX века // Проблемы внедрения результатов инновационных разработок: сборник статей междунар. науч.-практ. конф. (25 ноября 2015 г., Пермь) / под ред. А.А. Сукиасяна. Уфа: Аэтерна, 2015. С. 182-184.

5. Хрестоматия по истории школы и педагогики в России (до Великой Октябрьской социалистической революции) / сост. С.Д. Егоров. М.: Просвещение, 1986. $432 \mathrm{c}$.

6. Райков Б.Е. Пути и методы натуралистического просвещения. М.: Изд-во АПН РСФСР, 1960. 485 с.

7. Зверев И.Д., Трайтак Д.И. Методика преподавания биологии: исторический очерк // Биология в школе. 1987. № 5. С. 22-26.

8. Теряев А.М. Начальные основания ботанической философии. СПб.: Изд-во при Имп. Акад. наук, 1829. $156 \mathrm{c}$.

9. Кастальский И. Ботаника для юношества, содержащая начальные основания ботаники и изображения 102 растений. СПб.: Глазунов, 1826. 276 с.

10. Коротов В.М. Основоположник теории развития личности // Педагогика. 1994. № 4. С. 79-88.

11. Ушинский К.Д. Избранные педагогические сочинения: В 2 т. Т. 2 / под ред. Н.И. Пискунова. М.: Педагогика, 1974. 438 с.

12. Бекетов А.Н. О приложении индуктивного метода мышления к преподаванию естественной истории в гимназиях // ЖМН Пр. 1863. № 12. С. 14-18.

13. Богданов А.П. Зоология и зоологическая хрестоматия: В 3 т. М.: Грачев и Ко, 1862. 1865. 3 т.

14. Любен А. Руководство к систематическому изучению ботаники для школ и самообучения: В 2 т. СПб.: Головачев, 1869.

15. Раевский Н.И. Ботаника для реальных училищ. М.: Лисснер и Ромон, 1890. 270 с. 
16. Михайлов Д.С. Приготовительный курс зоологии. СПб.: Огризко, 1862. 139 с.

17. Сент-Илер К.К. Элементарный курс зоологии. СПб.: Товарищество «Общественная польза», 1874. $250 \mathrm{c}$.

18. Трайтак Д.И. Александр Яковлевич Герд (18411888) // Биология в школе. 1988. № 6. С. 20-21.

19. Лесгафт П.Ф. Семейное воспитание ребенка и его значение: В 2 т. СПб.: Товарищество художественной печати, 1900.

20. Половцов В.В. Основы общей методики естествознания. М.: Сытин, 1907. 276 с.
21. Игнатьев Б., Соколов С. Наблюдай природу. М.; Петроград: Госиздат, 1923. 96 с.

22. Спенсер Г. Воспитание умственное, нравственное и физическое. СПб.: Губинский, 1906. 230 с.

23. Рибо Т. Опыт исследования творческого воображения: Пер. с фр. СПб.: Пантелеев, 1901. 232 с.

24. Бинэ А., Симон Т. Развитие интеллекта детей. М.: Саблин, 1911. 162 с.

25. Румянцев Е. Как изучалась и изучается душевная жизнь детей? // Душевная жизнь детей. М., 1910. С. 4-65.

26. Севрук Л.С. Методика начального курса естествоведения. СПб., 1902. 428 с.

\section{THE PROBLEM OF STUDENTS' DEVELOPMENT IN THE THEORY AND PRACTICE OF THE NATIONAL SCHOOL UNTIL 1917 (ON THE EXAMPLE OF NATURAL SCIENCE)}

(C) 2018

Lamekhova Elena Anatolievna, candidate of pedagogical sciences, associate professor of General Biology and Physiology Department South Ural State Humanitarian Pedagogical University (Chelyabinsk, Russian Federation)

Abstract. The paper deals with the problem of interrelation between education, upbringing and training of students while studying natural sciences, which has always been interesting for teachers and methodologists. This problem is especially urgent now in connection with the further implementation of the GEF of secondary general education, which aims the school to create conditions for students' development and self-realization. The paper considers interpretation of the relationship between teaching, upbringing and development in the educational process in Russian pedagogy in the period up to 1917. It is noted that views on education and upbringing of children in Russia and Europe developed roughly at the same time. Throughout the entire historical period, there was a struggle between supporters of the new education, advocating rapprochement with advanced Russian and Western European science and Russian clergy, preaching church dogma and their opponents, denying any development at all. Long enough unresolved problems were the lack of unified programs for all educational institutions and established terms of training. Principal changes in the system of domestic education are associated with scientific and pedagogical activities of M.V. Lomonosov and his followers. It emphasizes the importance of the idea that appeared in the writings of teachers in the middle of the $19^{\text {th }}$ century. It advised to take into account the age and individual inclinations of children and develop a new methodology based on children's activity and independence, which made it possible to pass to the inductive path of instruction. The process of natural science study from the nineteenth century is regarded as the most effective means of developing the sense organs, logical thinking and observation. It also explains the need to combine inductive and deductive teaching methods and justifies the need to use natural objects, experiments and observations in nature for students' development.

Keywords: training; upbringing; development; federal state educational standard of secondary general education; self-realization; natural science; textbooks; teaching aids; language of science and education; pedagogical problems; didactic problems; methodical problems; inductive deductive teaching methods; biological method.

\section{ПРОВЕРКА И ОЦЕНИВАНИЕ СФОРМИРОВАННОСТИ ПРОФЕССИОНАЛЬНЫХ КОМПЕТЕНЦИЙ: ПРОБЛЕМЫ И ПУТИ ИХ РЕШЕНИЯ (НА МАТЕРИАЛЕ ДИСЦИПЛИНЫ/МОДУЛЯ «МЕТОДИКА ОБУЧЕНИЯ БИОЛОГИИ»)} (C) 2018

Марина Антонина Васильевна, кандидат педагогических наук, доцент кафедры биологии, географии и химии

Арзамасский филиал Национального исследовательского Нижегородского государственного университета им. Н.И. Лобачевского (г. Арзамас, Нижегородская область, Российская Федерачия)

Галкина Елена Александровна, кандидат педагогических наук, доцент кафедры физиологии человека и методики обучения биологии Красноярский государственный педагогический университет им. В.П. Астафьева (2. Красноярск, Российская Федерачия)

Макарова Ольга Борисовна, кандидат педагогических наук, доцент кафедры зоологии и методики обучения биологии

Новосибирский государственный педагогический университет (г. Новосибирск, Российская Федерация)

Аннотащия. В данной статье на примере дисциплины/модуля «Методика обучения биологии» основной профессиональной образовательной программы направления подготовки 44.03.05 Педагогическое образова- 